\title{
Spray Application Factors and Plant Growth Regulator Performance: IV. Dose Response Relationships
}

\author{
Moritz Knoche ${ }^{1}$ \\ Research Institute for Agrobiology and Soil Fertility (AB-DLO), P.O. Box 14, 6700 AA Wageningen, \\ The Netherlands \\ Norman K. Lownds and Martin J. Bukovac \\ Department of Horticulture, Michigan State University, East Lansing, MI 48824
}

AdDitional INDEX wORDs. daminozide, gibberellic acid, carrier volume, spray volume, droplet size, bean, Phaseolus vulgaris

\begin{abstract}
Effect of carrier volume (range 119 to $668 \mathrm{~L} \cdot \mathrm{ha}^{-1}$ ) on dose response relationships of daminozide and GA $\mathrm{A}_{3}$ was investigated using bean (Phaseolus vulgaris $L$.) seedlings as a model system. Carrier volume was varied by altering nozzle travel speed thereby maintaining constant flow rate and droplet size. Response was indexed by inhibition (daminozide) or stimulation $\left(\mathrm{GA}_{3}\right)$ of elongation of first plus second internodes above primary leaves 14 days after spray application. Increasing dose by increasing concentration and/or increasing carrier volume at constant concentration increased response. For a given dose retained, response to daminozide was related positively to carrier volume, while $\mathbf{G A}_{3}$ response was not affected. Chemical names used: butanedioic acid mono(2,2-dimethylhydrazide) (daminozide); gibberellic acid (GA $)_{3}$.
\end{abstract}

Spray application in horticultural and agronomic crops is changing rapidly from traditional high-volume to low-volume (LV) application (Allen et al., 1986; Bukovac et al., 1986). Current recommendations for LV applications to fruit trees are often based on applying a given dose in a range of carrier volumes. Such recommendations imply that performance is independent of carrier volume at constant dose. However, data from spraying trials indicate, that inconsistency in plant growth regulator performance may be related to differences in spray volume used (Table 1). For example, response to ethephon [(2-chloroethyl) phosphonic acid; Rhone Poulenc, Research Triangle Park, N.C.] increased consistently when carrier volume was decreased (Bukovac, 1981; Olson et al., 1977), but performance of naphthaleneacetic acid (NAA; Rhone Poulenc), Accel (formulation of benzyladenine plus $\mathrm{GA}_{4+7}$; Abbott Lab., North Chicago, Ill.), fenoprop [2-(2,4,5-trichlorophenoxy)propionic acid; Rhone Poulenc], and $\mathrm{GA}_{3}$, (Abbott Lab.) was not affected by spray volume (Black et al., 1994; Bukovac, unpublished data; Hull et al., 1995). Also, daminozide performance was related positively to carrier volume in apple [Malus sylvestris (L.) Mill. var. domestica (Borkh.) Mansf.] (Rogers and Krestensen, 1973), but not in sour cherry [Prunus cerasus (L.)] (Bukovac, 1981).

Most of the information available on carrier volume effects has been generated in field studies using commercial application equipment where spray parameters are difficult to control. Frequently, flow rate was changed to achieve LV applications and hence, the effect of carrier volume was confounded by a simultaneous change in droplet size of the spray pattern (Allen et al., 1986; Rogers and Krestensen, 1973). Furthermore, fruit tree canopies represent a complex target and distribution of the dose and response may vary within a tree.

Received for publication 16 Mar. 1999. Accepted for publication 29 Oct. 1999. This research was supported in part by the Michigan Agricultural Experiment Station, grants from the U.S. Department of Agriculture, Agricultural Research Service (SCA 58-3607-5-140), and the Multi-Year Crop Protection Program of the Dutch Ministry for Agriculture. The authors are grateful to Ross D. Brazee, Robert D. Fox, and the late Donald L. Reichard for extensive discussions and image analysis. The cost of publishing this paper was defrayed in part by the payment of page charges. Under postal regulations, this paper therefore must be hereby marked advertisement solely to indicate this fact.

${ }^{1}$ Current address: Institute for Agronomy and Crop Science, Dept. of Horticulture, Martin-Luther-University Halle-Wittenberg, 06099 Halle, Germany.
To investigate the effect of carrier volume on performance of plant growth regulators in a more critical manner, we selected a model system using bean (Phaseolus vulgaris) seedlings and the growth regulators daminozide and $\mathrm{GA}_{3}$. These compounds were chosen, because 1) they represent growth regulators differing in polarity, 2) both induce rapid and marked effects on shoot elongation that can be quantified readily, and 3) information on droplet size and volume effects is available under controlled conditions (Knoche et al., 1998; Knoche and Bukovac, 1999 and 2000).

\section{Materials and Methods}

Plant material. Bean seed of two cultivars, determinate 'Green Ruler' (GR) for daminozide assay and indeterminate 'Black Seeded Blue Lake' (BSBL) for $\mathrm{GA}_{3}$ assay, were sown (three or four seeds per pot) in peat pots ( 0.58 -L volume) filled with a commercial growing medium (PROMIX BW; Premier Brands, New Rochelle, N.Y.). Following emergence, plants were selected for uniformity and freedom from defects and thinned to one plant per pot. Plants were watered daily. Fertilizer was provided either initially with the growing medium $(14 \mathrm{~N}-4.2 \mathrm{P}-$ 11.6K Osmocote at $8 \mathrm{~g} \cdot \mathrm{L}^{-1}$; Scotts-Sierra Horticultural Prod. Co., Marysville, Ohio) or at weekly intervals by fertigation with Peters 20N-8.8P-16.6K water-soluble fertilizer (Scotts-Sierra Horticultural Prod. Co.) at an N concentration equivalent to $50 \mathrm{mg} \cdot \mathrm{L}^{-}$ ${ }^{1}$. Growing conditions were a growth chamber set at 16-h day/8h night temperatures of $25 / 20 \pm 2{ }^{\circ} \mathrm{C}$ and $45 / 62 \pm 5 \%$ relative humidity with a 16-h photoperiod provided by cool-white fluorescent lamps (F72T12 CW-1500; General Electric Co., Cleveland, Ohio) at $200 \mu \mathrm{mol} \cdot \mathrm{m}^{-2} \cdot \mathrm{s}^{-1}$ photosynthetic active radiation, as measured with a quantum-radiometer-photometer (LI-185; LI-COR, Lincoln, Nebr.), at plant level and supplemented by $1 \%$ red light (tungsten filament bulbs). Plants were maintained under these conditions for the entire experimental period except when removed $(\approx 2 \mathrm{~h})$ for treatment 7 or $8 \mathrm{~d}$ after seeding.

Growth REGUlators. Spray solutions were prepared with deionized water using daminozide (>99\% pure, technical grade; Uniroyal Chemical Corp., Middlebury, Conn., or analytical grade; Sigma Chem. Co., St. Louis, Mo.) and gibberellic acid $\left(\mathrm{GA}_{3}\right.$ content $>90 \%$; Sigma Chemical Co.). $\mathrm{GA}_{3}$ concentrations were based on a $\mathrm{GA}_{3}$ content of $100 \%$. 
Table 1. Documented responses of growth regulator performance when applied in reduced carrier volumes in tree fruit species.

\begin{tabular}{|c|c|c|c|c|c|}
\hline $\begin{array}{l}\text { Growth } \\
\text { regulator }\end{array}$ & Species & $\begin{array}{c}\text { Carrier } \\
\text { vol } \\
\text { range } \\
\left(\mathrm{L} \cdot \mathrm{ha}^{-1}\right)\end{array}$ & $\begin{array}{l}\text { Response } \\
\text { index }\end{array}$ & $\begin{array}{c}\text { Effect on } \\
\text { performance }^{\mathrm{z}}\end{array}$ & Reference \\
\hline $\mathrm{Accel}^{\mathrm{y}}$ & Apple & $500-2000$ & Fruit size, yield & No effect & Hull et al. (1995) \\
\hline \multirow{2}{*}{ Daminozide } & Apple & $93-1870$ & Fruit drop & Decreased & Rogers and Krestensen (1973) \\
\hline & Sour cherry & $94-2350$ & Fruit removal force & No effect & Bukovac (1981) \\
\hline \multirow[t]{2}{*}{ Ethephon } & Sweet cherry & $118-2350$ & Fruit removal force & Increased & Bukovac (1981) \\
\hline & Walnut & 935-2804 & Nut removal (\%), hullability & Increased & Olson et al. (1977) \\
\hline Fenoprop $^{\mathrm{x}}$ & Apple & 159-3972 & Fruit drop & No effect & Bukovac, unpublished \\
\hline $\mathrm{GA}_{3}$ & Sour cherry & $234-1738$ & Flowering & No effect & Bukovac, unpublished \\
\hline NAA & Apple & $230-2100$ & Thinning, fruit size & No effect & Black et al. (1994) \\
\hline
\end{tabular}

${ }^{\mathrm{z}}$ Effect relative to response obtained from high volume application.

y Formulation of benzyladenine $(1.8 \%)+\mathrm{GA}_{4+7}(0.18 \%)$.

${ }^{\mathrm{x}}$ Formulation of 2-(2,4,5-trichlorophenoxy) propionic acid.
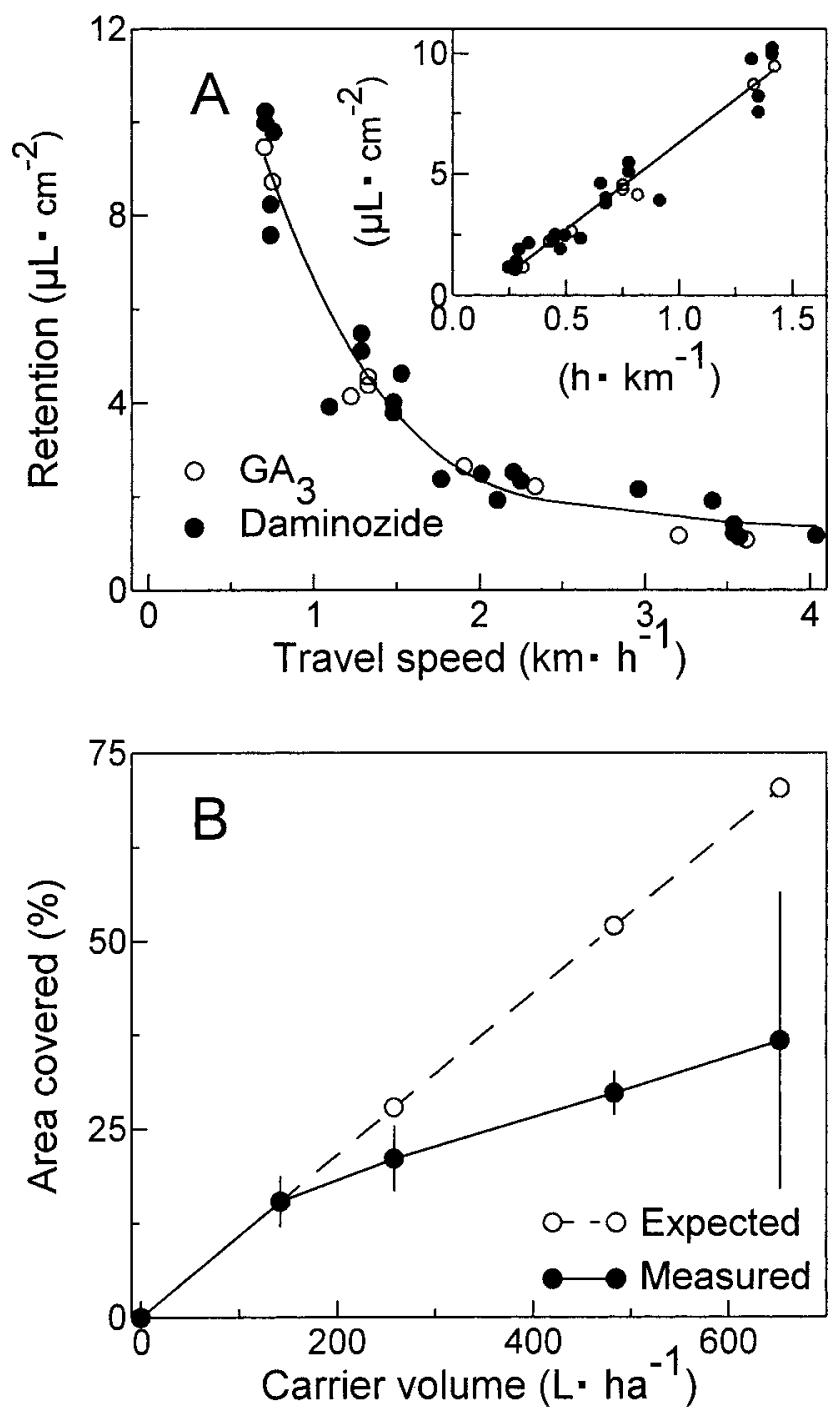

Fig. 1. (A) effect of nozzle travel speed on the spray volume retained per unit leaf area of primary leaves of bean seedlings (inset: spray retention vs. the inverse of travel speed) and (B) effect of carrier volume on actual percentage leaf area covered compared with theoretical coverage expected if spray impacted and remained and dried as discrete droplets.
SPRAY APPLICATION AND BIOLOGICAL RESPONSE. Effect of carrier volume on daminozide inhibition and $\mathrm{GA}_{3}$ promotion of internode elongation was investigated following spray application using an experimental track sprayer. Concentrations of spray solutions for daminozide and $\mathrm{GA}_{3}$ were $150,300,600,1200$, and 2400 $\mathrm{mg} \cdot \mathrm{L}^{-1}$ and $2.5,5,10,20$, and $40 \mathrm{mg} \cdot \mathrm{L}^{-1}$, respectively. The $\mathrm{pH}$ of daminozide solutions averaged 3.6 (range 3.5 to 3.9; water control 5.5), while $\mathrm{pH}$ of $\mathrm{GA}_{3}$ solutions decreased from 4.8 to 3.8 as concentration increased from 2.5 to $40 \mathrm{mg} \cdot \mathrm{L}^{-1}$. The track sprayer was equipped with a conventional flat fan spray nozzle (8002; Spraying Systems, Wheaton, Ill.) mounted on a variable speed transport carriage. Seedlings were positioned $\approx 46 \mathrm{~cm}$ below the nozzle with primary leaves orientated perpendicular to travel of the nozzle. The flow rate averaged $258 \mathrm{~mL} \cdot \mathrm{min}^{-1}$ at $39.6 \mathrm{kPa}$ measured at the spray nozzle. Specified carrier volumes (range 138 to 668 $\mathrm{L} \cdot \mathrm{ha}^{-1}$ ) were achieved by varying travel speed $\left(3.6\right.$ to $0.75 \mathrm{~km} \cdot \mathrm{h}^{-1}$ ). Orifice size and flow rate were kept constant. Under these conditions, volume median diameter of spray droplets was $356 \pm 43 \mu \mathrm{m}$ $(\mathrm{SE}, \mathrm{n}=3)$. Sprays were applied to primary bean leaves at the midpoint of the photoperiod $\pm 1 \mathrm{~h}$ at $25 \pm 3^{\circ} \mathrm{C}$. Plants were selected further so that the length of the first internode was $<1 \mathrm{~cm}$. When necessary, leaves were supported from below (deviation from horizontal $\left\langle 20^{\circ}\right.$ ) to ensure a similar and full plan leaf area exposure to the spray. Plants were returned immediately to the growth chamber after spraying, randomized, staked with bamboo when dry, and allowed to grow for $14 \mathrm{~d}$. Unless otherwise specified, elongation of first plus second internodes was determined with 10 replications per concentration. Dose response relations established in previous studies may be linearized using the following transformations (Knoche et al., 1998). For daminozide, log internode length $(\mathrm{cm})=$ $-0.27 \times \log \left(\right.$ concn, $\left.\mathrm{g} \cdot \mathrm{L}^{-1}\right)+0.79, r^{2}=0.940^{* *}$; for $\mathrm{GA}_{3}$, internode length $(\mathrm{cm})=19.0 \times \log \left(\right.$ concn, $\left.\mathrm{mg} \cdot \mathrm{L}^{-1}\right)+18.8, r^{2}=0.986^{* *}$.

Data for the highest $\mathrm{GA}_{3}$ concentration were excluded from this analysis, since $\mathrm{GA}_{3}$ internode elongation response was saturated at doses exceeding $7.5 \mu \mathrm{g} / \mathrm{leaf}$ (see Fig. 2B in Knoche et al., 1998).

SPRAY RETENTION, COVERAGE, AND SURFACE TENSION. Retention was measured gravimetrically for each pass of the nozzle. Primary leaves of comparable plants were excised, weighed, positioned in the spray path at the same height and orientation as for the record plants, sprayed, and then reweighed. Leaf area was determined using a leaf area meter (model LI-3000; LI-COR). A maximum retention value of $\approx 6.7 \mu \mathrm{L} \cdot \mathrm{cm}^{-2}$ (equivalent to 665 $\mathrm{L} \cdot \mathrm{ha}^{-1}$ ) was calculated, when spraying plants just short of runoff.

Spray distribution and leaf coverage were assessed by spraying leaves with a $2 \%$ nigrosin dye solution using the same sprayer settings. Leaves were allowed to dry, excised, positioned between layers of botanical blotting paper, pressed, and stored in the 


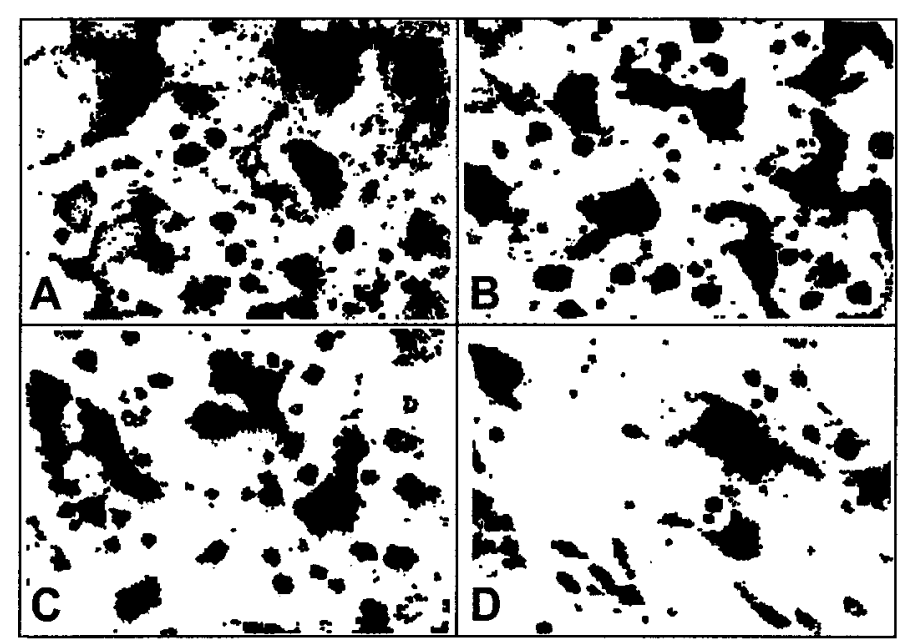

Fig. 2. Representative images of spray deposition on primary leaves of bean at carrier volumes of (A) 653, (B) 483, (C) 258, and (D) $142 \mathrm{~L} \cdot \mathrm{ha}^{-1}$ applied with a flat-fan nozzle. Corresponding leaf area covered was $34.4 \%, 31.3 \%, 21.0 \%$, and $15.3 \%$, respectively. Each image represents an original area sampled of $0.85 \mathrm{~cm}$ $\times 1.24 \mathrm{~cm}$ or $1.05 \mathrm{~cm}^{2}$.

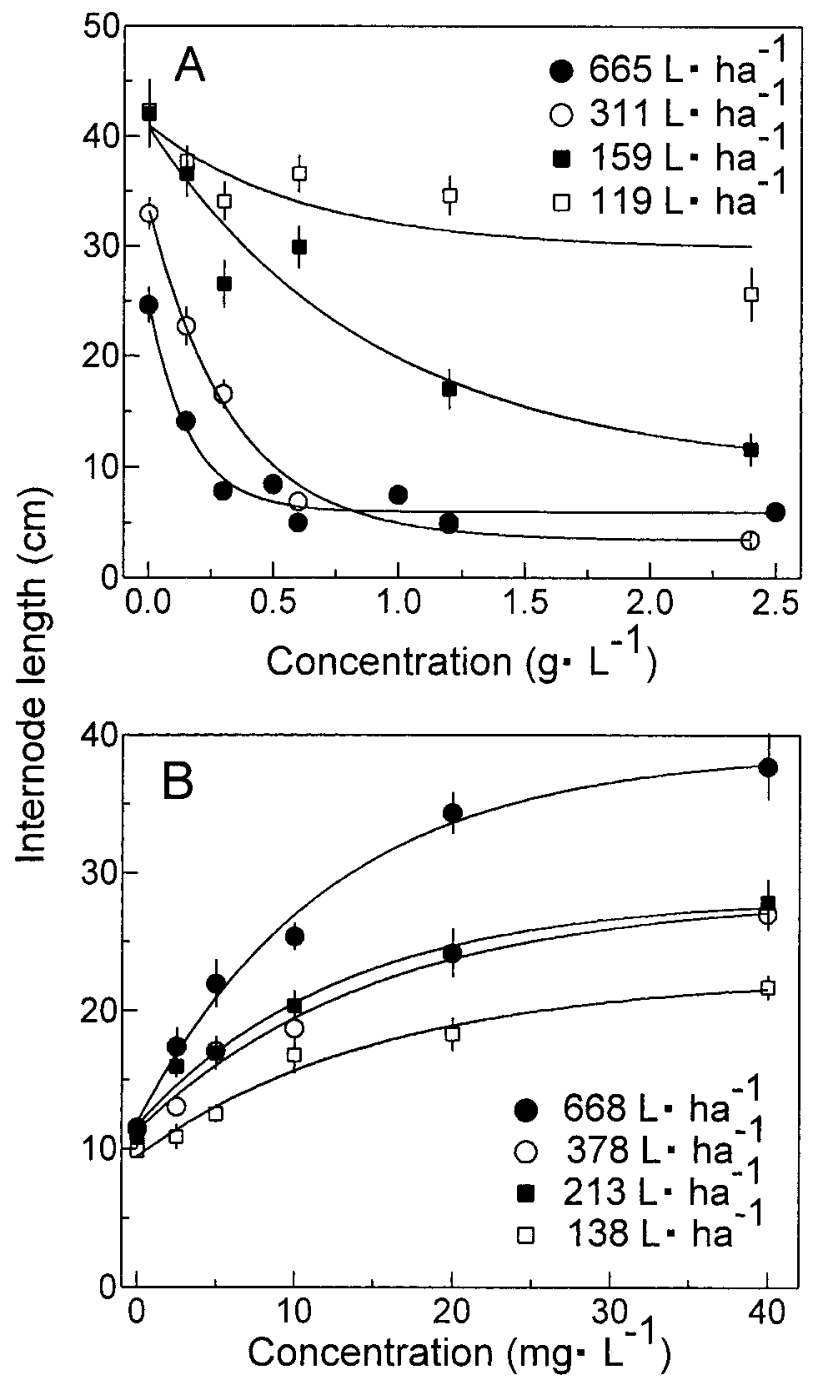

Fig. 3. Effect of spray concentration and carrier volume on (A) daminozide inhibition and (B) $\mathrm{GA}_{3}$ promotion of internode elongation in bean seedlings. laboratory. Spray coverage and distribution were determined by image analysis (Dapple System, Sunnyvale, Calif.). Leaves were viewed directly, and percentage coverage was calculated. The average of three randomly selected areas $\left(\approx 1 \mathrm{~cm}^{2}\right.$ each $)$ per leaf represented one observation and determinations were carried out using five replications.

Surface tension of daminozide (150 to $2400 \mathrm{mg} \cdot \mathrm{L}^{-1}$ ) and $\mathrm{GA}_{3}$ (2.5 to $40 \mathrm{mg} \cdot \mathrm{L}^{-1}$ ) solutions was determined using a surface tensio-meter (model K 6; Krüss, Hamburg, Germany). A 10-mL aliquot of spray solution was transferred into a glass petri dish, equilibrated for $1 \mathrm{~h}$ and surface tension determined. Each determination was replicated three times.

Statistical Analysis. Owing to the size of an experimental unit (10 replications per concentration, six concentrations per carrier volume, and four carrier volumes), and complexity and logistics of applications of uniform sprays of a given volume and droplet size, the treatments (carrier volume, concentration, travel speed) were repeated in time. An appropriate control was included in each and spray output, deposition on plants and travel speed was measured for each treatment. Where appropriate, data were subjected to analysis of variance. Standard errors (all figures except for Fig. 4A) or 95\% confidence limits (Fig. 5) were
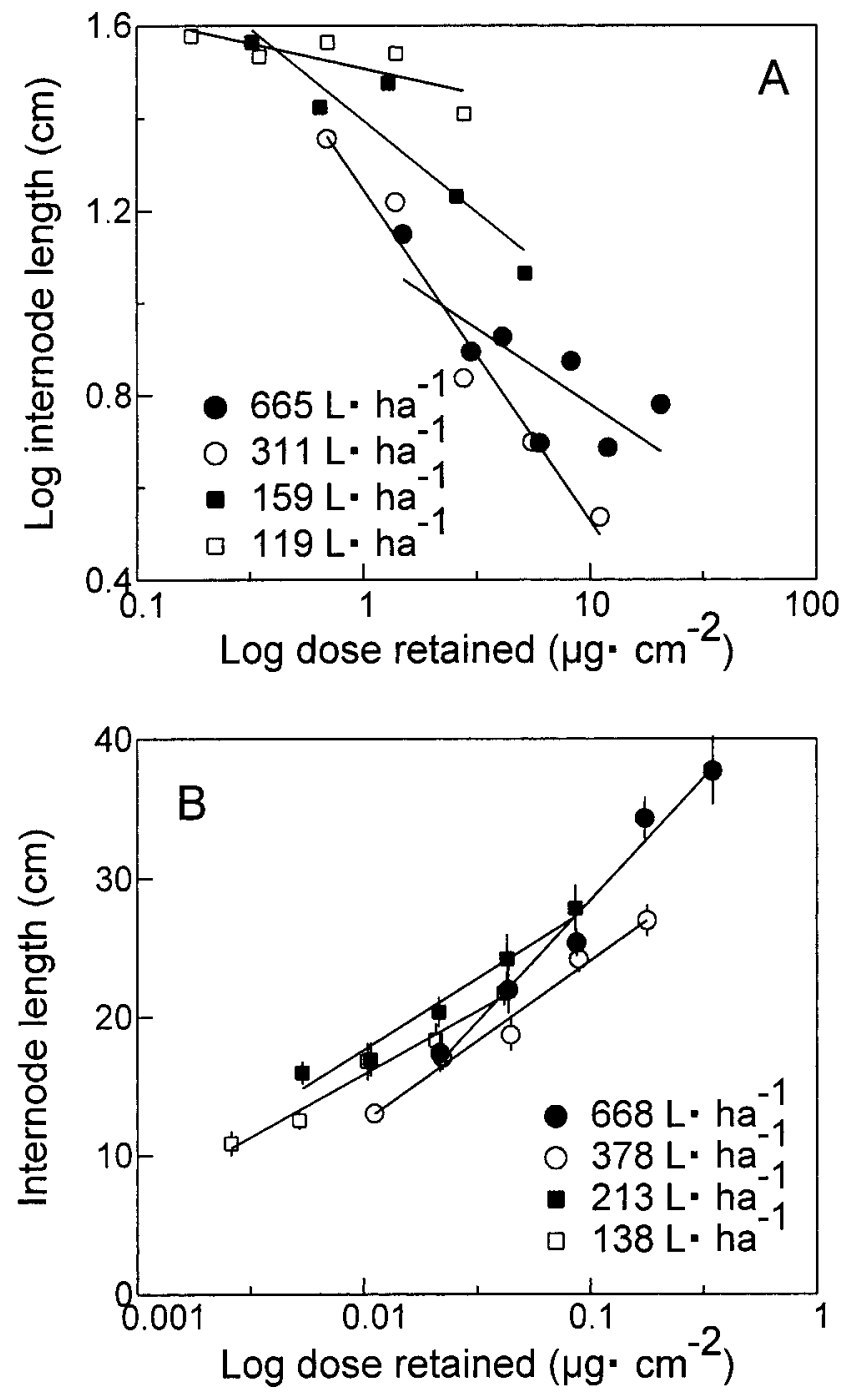

Fig. 4. (A) daminozide inhibition and (B) $\mathrm{GA}_{3}$ promotion of internode elongation of bean seedlings as a function of dose retained per unit leaf area. For regression equations see Table 2 . 
Table 2. Regression equations for dose response relationships for daminozide or $\mathrm{GA}_{3}$ and internode elongation in bean seedlings. ${ }^{\mathrm{z}}$

\begin{tabular}{|c|c|c|c|c|}
\hline \multirow{2}{*}{$\begin{array}{l}\text { Growth } \\
\text { regulator }\end{array}$} & \multirow{2}{*}{$\begin{array}{c}\text { Carrier } \\
\text { vol } \\
\left(\mathrm{L} \cdot \mathrm{ha}^{-1}\right)\end{array}$} & \multicolumn{2}{|c|}{$\begin{array}{c}\text { Regression coefficient } \\
\pm \mathrm{SE}\end{array}$} & \multirow{2}{*}{$\begin{array}{l}\text { Coefficient of } \\
\text { determination } \\
\qquad\left(r^{2}\right)\end{array}$} \\
\hline & & $\mathrm{a}$ & $\mathrm{b}$ & \\
\hline \multirow[t]{4}{*}{$\overline{\text { Daminozide }}$} & 119 & $-0.11 \pm 0.05$ & $1.51 \pm 0.02$ & $0.605^{\mathrm{NS}}$ \\
\hline & 159 & $-0.40 \pm 0.09$ & $1.40 \pm 0.04$ & $0.873^{*}$ \\
\hline & 311 & $-0.72 \pm 0.08$ & $1.25 \pm 0.05$ & $0.968^{* *}$ \\
\hline & 665 & $-0.33 \pm 0.11$ & $1.11 \pm 0.10$ & $0.621^{*}$ \\
\hline \multirow[t]{4}{*}{$\mathrm{GA}_{3}$} & 138 & $9.1 \pm 0.7$ & $34.1 \pm 1.5$ & $0.981^{\text {** }}$ \\
\hline & 213 & $10.3 \pm 1.1$ & $38.2 \pm 1.8$ & $0.969^{* * *}$ \\
\hline & 378 & $11.6 \pm 0.9$ & $35.7 \pm 1.3$ & $0.981^{* * *}$ \\
\hline & 668 & $17.6 \pm 1.6$ & $46.0 \pm 1.8$ & $0.975^{* *}$ \\
\hline
\end{tabular}

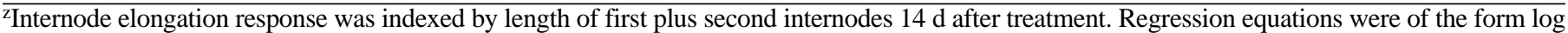
internode length $(\mathrm{cm})=\mathrm{a} \times \log \left(\operatorname{dose}, \mu \mathrm{g} \cdot \mathrm{cm}^{-2}\right)+\mathrm{b}$ for daminozide and Internode length $(\mathrm{cm})=\mathrm{a} \times \log \left(\operatorname{dose}, \mu \mathrm{g} \cdot \mathrm{cm}^{-2}\right)+\mathrm{b}$ for GA 3 . Ns, ${ }^{*}, * *$ Nonsignificant or significant at $P \leq 0.05$ or 0.01 , respectively.

included in all graphs. Where not shown, se bars were smaller than data symbols. The symbols $*, * *, * * *$ indicate significance of coefficients of determination $\left(r^{2}\right)$ of linear regression analysis at $P \leq 0.05,0.01$, or 0.001 , respectively. Unless otherwise specified, regression analysis was conducted using treatment means.

\section{Results and Discussion}

Increasing nozzle travel speed decreased the volume of spray solution retained per unit leaf area (Fig. 1A). Plotting the inverse of

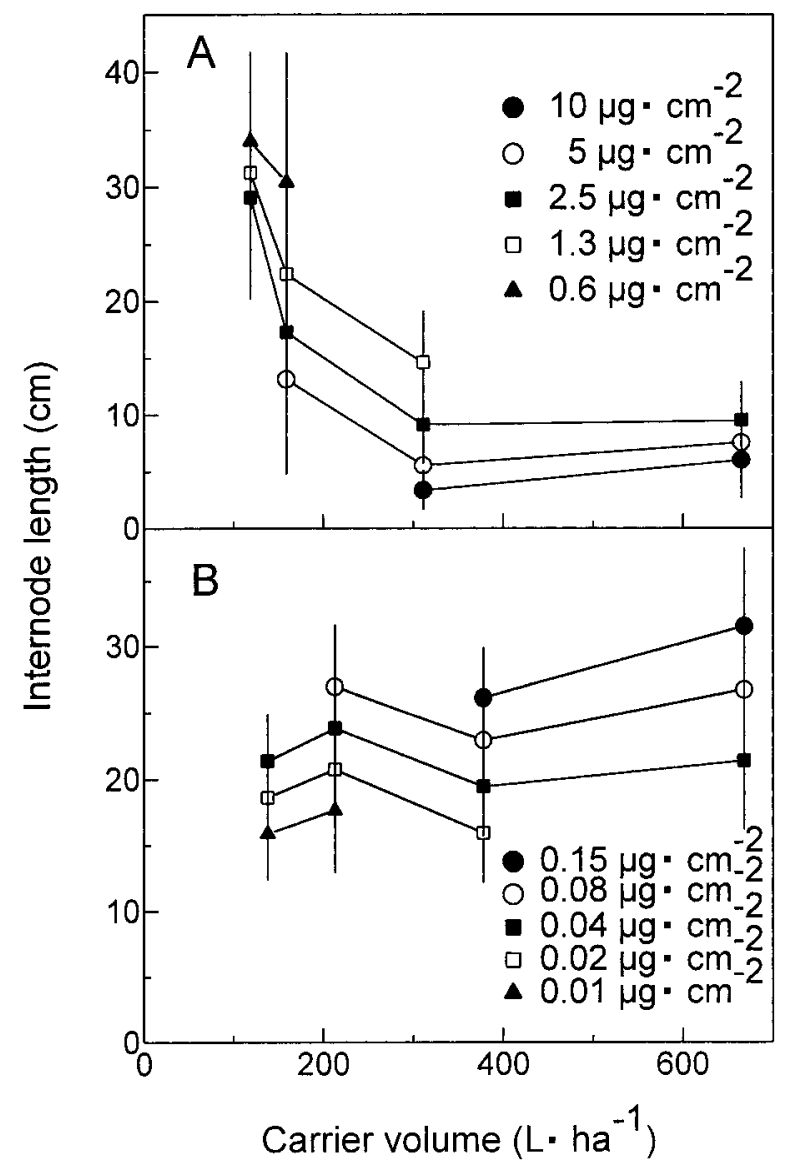

Fig. 5. Predicted effects of carrier volume on (A) daminozide-inhibition and (B) $\mathrm{GA}_{3}$ promotion of elongation of first plus second internodes of bean seedlings. Vertical bars represent $95 \%$ confidence limits. For details see text. travel speed against spray retention yielded a significant linear relationship, Retention $\left(\mu \mathrm{L} \cdot \mathrm{cm}^{-2}\right)=7.2 \times$ speed $^{-1}\left(\mathrm{~h} \cdot \mathrm{km}^{-1}\right)-0.88$, $r^{2}=0.977^{* * *}$, indicating that retention efficiency was independent of the spray volume applied at the speeds and volumes used (Fig. 1A, inset). This may be expected, since 1) droplet size was maintained constant and that changing travel speed only altered the number of droplets impacting on the leaf surface, 2) surface tension of daminozide and $\mathrm{GA}_{3}$ solutions were independent of concentration and not significantly different from water, and 3) there was no significant runoff of spray solution from the leaf surface in this experiment.

A positive relationship was obtained between leaf coverage and the volume applied (Fig. 1B). Increasing spray volume from 142 to $653 \mathrm{~L}^{-h^{-1}}$ increased spray coverage from $15.3 \%$ to $36.7 \%$ (Fig. 1B and 2). However, the increase in coverage was less than expected if droplets impacted and spread independently (solid vs. dotted line, Fig. 1B). This observation suggested that an increasing number of droplets coalesced so that deposits overlapped as carrier volume was increased (see also Fig. 2).

Effects of daminozide on inhibition and $\mathrm{GA}_{3}$ on promotion of internode elongation were related positively to the concentration of the active ingredient (a.i.) and/or carrier volume (Fig. 3A and B). Since spray retention has been measured as a function of nozzle travel speed, the amount of daminozide and $\mathrm{GA}_{3}$ retained per unit leaf area can be calculated from retention data for any given concentration and carrier volume. Linearizing dose response relations by appropriate transformations noted earlier and plotting response vs. dose retained per unit leaf area yielded the relationships illustrated in Fig. 4 (for regression equations see Table 2). Since a constant concentration range was applied at different carrier volumes, the amounts of a.i. retained per unit leaf area differed among spray volumes. However, doses in the ranges of 1.5 to $2.8 \mu \mathrm{g} \cdot \mathrm{cm}^{-2}$ (daminozide) and 0.022 to $0.042 \mu \mathrm{g} \cdot \mathrm{cm}^{-2}$ $\left(\mathrm{GA}_{3}\right)$ were common to all carrier volumes (Fig. $4 \mathrm{~A}$ and $\mathrm{B}$ ), and for these ranges, internode elongation was calculated as a function of carrier volume.

Increasing carrier volume at constant daminozide dose decreased internode length (Fig. 5A). In contrast, $\mathrm{GA}_{3}$ promotion of internode elongation was independent of carrier volume (Fig. $5 \mathrm{~B})$. Absence of a carrier volume effect on $\mathrm{GA}_{3}$ performance was confirmed, when an approximately constant dose of $\mathrm{GA}_{3}$ per unit leaf area was applied in various carrier volumes (Table 3 ). While $\mathrm{GA}_{3}$ increased internode length compared to the control, there was no difference in response to a given dose delivered in different carrier volumes (Table 3 ). These data are consistent with 
Table 3. Effect of carrier volume at constant dose of $\mathrm{GA}_{3}$ on internode elongation in bean seedlings.

\begin{tabular}{|c|c|c|c|c|c|}
\hline \multirow{2}{*}{$\begin{array}{l}\text { Carrier } \\
\text { vol } \\
\left(\mathrm{L} \cdot \mathrm{ha}^{-1}\right)\end{array}$} & \multirow{2}{*}{$\begin{array}{c}\text { Concn } \\
\left(\mathrm{mg} \cdot \mathrm{L}^{-1}\right)\end{array}$} & \multirow{2}{*}{$\begin{array}{l}\mathrm{GA}_{3} \\
\text { retention } \\
\left(\mu \mathrm{g} \cdot \mathrm{cm}^{-2}\right)\end{array}$} & \multicolumn{3}{|c|}{$\begin{array}{l}\text { Internode length }{ }^{\mathrm{z}} \\
(\mathrm{cm})\end{array}$} \\
\hline & & & First & Second & Third \\
\hline Control & --- & --- & $3.2 \mathrm{a}$ & $2.5 \mathrm{a}$ & $5.5 \mathrm{a}$ \\
\hline 160 & 40 & 0.046 & $4.0 \mathrm{a}$ & $5.0 \mathrm{~b}$ & $12.6 \mathrm{~b}$ \\
\hline 269 & 20 & 0.053 & $4.2 \mathrm{a}$ & $5.0 \mathrm{~b}$ & $12.5 \mathrm{~b}$ \\
\hline 420 & 10 & 0.041 & $3.7 \mathrm{a}$ & $5.5 \mathrm{~b}$ & $13.2 \mathrm{~b}$ \\
\hline 730 & 5 & 0.047 & $4.2 \mathrm{a}$ & $5.7 \mathrm{~b}$ & $13.3 \mathrm{~b}$ \\
\hline
\end{tabular}

${ }^{\mathrm{z}}$ Mean separation within columns by Duncan's multiple range test, $P \leq 0.05$.

earlier observations following droplet application of daminozide and $\mathrm{GA}_{3}$ to primary bean leaves (Knoche et al., 1998). Since retention efficiency on the easy-to-wet bean leaf surface was independent of carrier volume (Fig. 1A), effects on the growth regulator induced growth responses were most likely related to a carrier volume effect on foliar uptake and/or subsequent transfer stages. In our earlier studies we observed higher translocation (percentage of applied) at higher carrier volumes (Knoche and Bukovac, 1999 and 2000). Unfortunately, the coverage range investigated was markedly narrower $(0.3 \%$ to $10.6 \%)$ compared with the present study (15.3\% to $36.7 \%)$. Also, in our earlier study (Knoche and Bukovac, 2000) we observed phytotoxicity at low carrier volumes/high concentrations of daminozide. Thus, we do not know if the relationship obtained earlier fully applies to our present study, where no toxicity was observed.

Care must be taken in extrapolating our findings to other species that differ significantly in wettability. For spray solutions containing surfactants, retention efficiency and solution concentration, i.e., carrier volume, may be interrelated (Anderson et al., 1983; Reichard, 1988; Thomas and Hall, 1979). For difficult-towet leaf surfaces (contact angles $>90^{\circ}$ ) retention efficiency is expected to increase with decreasing carrier volume and this would increase performance. Furthermore, canopy architecture of crops may differ dramatically from the model system employed in our study and altering spray application parameters may alter canopy penetration of spray droplets thereby affecting performance.

In conclusion, our data confirm that performance of growth regulators may be affected by carrier volume. Hence, for a given response, the dose of a compound applied may be a function of carrier volume. At present, the data base for adjusting doses for a carrier volume effect is very limited. Research in this area is critically needed not only to increase plant growth regulator performance, but also to increase spray efficiency and reduce nonessential chemical input into the environment.

\section{Literature Cited}

Allen, J., D. Austin, and D. Butt. 1986. Improving the efficiency of top fruit spraying, p. 8-9. In: J. Hardcastle (ed.). Science, sprays and sprayers. Agr. Food Res. Council, Occasional Publication Series, London.

Anderson, N.H., D.J. Hall, and N.M. Western. 1983. The role of dynamic surface tension in spray retention. Proc. 10th Intl. Congr. Plant Protection 2:576 (abstr.).

Black, B.L., M.J. Bukovac, and J. Hull, Jr. 1994. Effects of NAA on fruit size of 'Delicious' apples. HortScience 29:472 (abstr.).

Bukovac, M.J. 1981. Performance of daminozide and ethephon when applied in low-volume sprays to sour and sweet cherry. Acta Hort. 120:25-29.

Bukovac, M.J., D.L. Reichard, and R.E. Whitmoyer. 1986. The spray application process: Central for the efficient use of growth regulators in tree fruits. Acta Hort. 179:33-45.

Hull, Jr., J., M.J. Bukovac, and B.L. Black. 1995. Effect of concentration and time of Accel application on cropping of selected cultivars. HortScience 30:765 (abstr.).

Knoche, M. and M.J. Bukovac. 1999. Spray application factors and plant growth regulator performance: II. Foliar uptake of $\mathrm{GA}_{3}$ and 2,4-D. Pest. Sci. 55:166-174.

Knoche, M. and M.J. Bukovac. 2000. Spray application factors and plant growth regulator performance: III. Interaction of daminozide uptake, translocation and phytotoxicity in bean seedlings. Pest Mgt. Sci. 56:4348.

Knoche, M., M.J. Bukovac, S. Nakagawa, and G.D. Crabtree. 1998. Spray application factors and plant growth regulator performance: I. Bioassays and biological response. Pest. Sci. 54:168-178.

Olson, W.H., G.S. Sibbet, G.L. Carnhill, and G.C. Martin. 1977. Lower ethephon rates effective in walnut harvest. Calif. Agr. 31:6-7.

Reichard, D.L. 1988. Drop formation and impaction on the plant. Weed Technol. 2:82-87.

Rogers, B.L. and E.R. Krestensen. 1973. Preharvest drop of 'Stayman' apples as influenced by SADH in dilute and concentrate form. HortScience 8:314-315.

Thomas, W.D.E. and D.J. Hall. 1979. Dynamic surface tension of some non-ionic surfactants at the solution/air surface, p. 107-116. In: Surface active agents. Soc. Chem. Ind., London. 